\title{
Sex difference and the role of leptin in the association between high-sensitivity $\mathrm{C}$-reactive protein and adiposity in two different populations
}

\author{
Isabelle Anne Rossi • Murielle Bochud • \\ Pascal Bovet · Fred Paccaud · Gérard Waeber • \\ Peter Vollenweider • Patrick Taffé
}

Received: 3 October 2011/Accepted: 23 February 2012/Published online: 6 March 2012

(C) Springer Science+Business Media B.V. 2012

\begin{abstract}
Elevated high-sensitivity C-reactive protein (hs-CRP) concentration is associated with an increased risk of cardiovascular disease but this association seems to be largely mediated via conventional cardiovascular risk factors. In particular, the association between hs-CRP and obesity has been extensively demonstrated and correlations are stronger in women than men. We used fractional polynomials - a method that allows flexible modeling of non linear relations - to investigate the dose/response mathematical relationship between hs-CRP and several indicators of adiposity in Caucasians (Switzerland) and Africans (Seychelles) surveyed in two population-based studies. This relationship was non-linear exhibiting a steeper slope for low levels of hs-CRP and a higher level in women. The observed sex difference in the relationship between hs-CRP and adiposity almost disappeared upon adjustment for leptin, suggesting that these sex differences might be partially mediated, by leptin. All these relationship were similar in Caucasians and Africans. This is the first report on a non-linear relation, stratified by gender, between hs-CRP and adiposity.
\end{abstract}

I. A. Rossi · M. Bochud ( $)$ · P. Bovet · F. Paccaud · P. Taffé Institute of Social and Preventive Medicine (IUMSP), Lausanne University Hospital and University of Lausanne, Route de la Corniche 2, 1066 Epalinges, Switzerland e-mail: murielle.bochud@chuv.ch

P. Bovet

Ministry of Health, Victoria, Republic of Seychelles

G. Waeber $\cdot$ P. Vollenweider

Department of Medicine, Internal Medicine, Lausanne

University Hospital, 1011 Lausanne, Switzerland
Keywords Africa $\cdot$ C-reactive protein - Obesity · Body mass index $\cdot$ Fat mass

\section{Background}

C-reactive protein (CRP) is a sensitive but unspecific acute phase protein, synthesized by the liver. Elevated high sensitivity CRP (hs-CRP) concentration is associated with cardiovascular disease [1-6], although this association largely depends on conventional cardiovascular risk factors [7]. In particular, hs-CRP level is directly associated with each single components of the metabolic syndrome [8-10] and predicts the development of the full syndrome [11]. The association between hs-CRP and adiposity has also been extensively documented $[9,12,13]$ especially with central abdominal adiposity $[14,15]$.

Correlations between hs-CRP and adiposity are stronger in women than men [14, 16-20]. This sex difference is also found in a Mendelian randomization analysis, suggesting a causal association in women but not in men [21]. Such a causal relationship was however not confirmed by other authors [22-24].

Given the paucity of available data regarding hs-CRP distribution in African populations and the increasing interest in hs-CRP for cardiovascular risk prediction, we investigated the relationship between hs-CRP and adiposity in two widely different populations, one in the African region and the other in Europe. Most studies that have explored the CRP-adiposity association used linear models, which may not appropriately reflect the true underlying relationship. The aim of this study was to explore the potential non-linearity of the CRP-adiposity relationship. For this, we used fractional polynomials-a modeling technique that allows to flexibly model non linear relations. 


\section{Method}

A population-based survey of cardiovascular risk factors was conducted in 2004 in the Seychelles (Seychelles Heart Study III) and was attended by 1,255 persons (participation rate of $80.2 \%$ ). The sampling frame, methods and main results of the survey have been described previously [25]. Eighty-six subjects were excluded from the present analysis because of missing data for the considered variables and the final sample comprised 1,169 persons (645 women, 524 men). The Ministry of Health approved the survey after technical and ethical reviews. Participants were free to participate and gave written informed consent. Current cigarette smoking was defined as smoking at least one cigarette per day. Questions on alcohol consumption were administered only to the participants who reported to have a drink at least once per month. Alcohol consumption was assessed by questions on drinking frequency and volume, which allowed calculating mean ethanol consumption per day. Physical activity was assessed using the Global Physical Activity Questionnaire (GPAQ) [26] and MET equivalent per week was calculated accordingly.

Weight was measured with a validated electronic scale (Seca) and height with fixed stadiometers (Seca). Body mass index was calculated as weight $(\mathrm{kg})$ divided by height (m) squared. Fat mass was measured using a noninvasive bioimpedance analyzer (Omron body fat monitor HBF300). Serum concentration of hs-CRP was measured using a latex-enforced immunonephelometry using the BN II (Dade Behring) method.

Regarding the Caucasian population (CoLaus study), the study population, methods and main results have been previously described [27]. Briefly, a simple non-stratified random selection of 19,830 subjects ( $35 \%$ of the source population) was drawn. Among those eligible, 6,188 persons attended the survey, with a participation rate of $41 \%$. The study was approved by the Ethics Committee of the University of Lausanne and participants gave written informed consent. Sixty-nine subjects were excluded from the present analysis because of missing data for one or more of the considered variables. The final sample comprised 6,119 persons (3,251 women, 2,937 men). Cigarette smoking, alcohol consumption and physical activity were defined for persons who smoked at the time of examination, drank alcohol at least once a day and had physical activity of at least 20 min twice a week or more.

Weight was measured to the nearest $0,1 \mathrm{~kg}$ using a Seca scale and height recorded to the nearest $0.5 \mathrm{~cm}$ with a Seca height gauge. Body fat was assessed by electrical bioimpedance with the Bodystat 1500 body mass analyzer (Bodystat Ltd. Isle of Man, UK). Plasma concentration of hsCRP was measured by immunoassay and latex HS (maximum inter- and intra-batch coefficients of variation:
4.6-1.3\%, American Laboratory Products Co., Windham, $\mathrm{NH}$ ) and leptin by ELISA (12.8-5.8\%) (American Laboratory Products Co., Windham, NH). HDL cholesterol was estimated by CHOD-PAP + PEG + cyclodextrin (3.6-0.9\%, Roche Diagnostics, $\mathrm{CH}$ ). Glucose was measured by glucose dehydrogenase $(2.1-1.0 \%)$ and insulin estimated by solidphase, two-site chemiluminescent immunometric assay (maximum intra-assay CV of $13.7 \%$, Diagnostic Products Corporation, Los Angeles, USA). The Homeostasis Model Assessment (HOMA) score to estimate insulin resistance was calculated from fasting blood glucose and serum insulin levels using a standard formula: plasma glucose $(\mathrm{mmol} / \mathrm{l}) \times$ plasma insulin $(\mathrm{mU} / \mathrm{l}) / 22.5)$ [28].

\section{Statistical analysis}

We used multivariable fractional polynomials to assess the best analytical form (i.e. mathematical transformation) of each continuous regressor included in the regression model [29]. This modeling technique is particularly useful when simple mathematical transformations of the explanatory variable, such as the logarithm or square root, do not allow linearizing the relation with the outcome (given the other predictors included in the model) [30]. Very briefly, a fractional polynomial is a family of mathematical transformations applied to a regressor, which depends on a few parameters to be estimated by the optimization algorithm. It includes as special cases the logarithmic, inverse or square root transformations, but allows for much richer dose/response profiles. All the analyses were stratified by gender, as we expected these relations to be different for men and women. Because of the potential causal role of hs-CRP on adiposity [21], this factor was considered as the independent variable of main interest. We considered ageadjusted, as well as fully-adjusted models (i.e. models including as regressors age (continuous), smoking (current or non smoker), alcohol consumption (continuous for Seychelles Heart Study III and categorical for Colaus) and physical activity (continuous for Seychelles Heart Study III and categorical for Colaus), in addition to hs-CRP). Models with fat mass as the outcome variable were further adjusted for height. According to Abdullah et al. [31] who described an independent association between hs-CRP and leptin in women, models were further adjusted for leptin. For hs-CRP, we used percentile 95 as cut-off as a robust statistical approach based on trimming $(>9.9 \mathrm{mg} / \mathrm{l}$ for men and $>15.2$ for women for the Seychelles, $>8.1 \mathrm{mg} / \mathrm{l}$ for men and $>9.8$ for women for Colaus), because the distribution of hs-CRP differs between men and women in Caucasian and African populations. $P$ values were twosided and values less than 0.05 were considered as significant. Analyses were performed using Stata11.1 software (Stata Corp., College Station, Texas, USA). 


\section{Results}

The baseline characteristics of the Seychelles and Colaus study participants, stratified by sex, are presented in Table 1. Overall, in the Seychelles, far less women than men reported to drink alcohol or to smoke. Women had higher BMI, fat mass, mean and median hs-CRP levels than men. By contrast, more Caucasian women smoked or drank alcohol, and women had lower BMI than men. Women had higher median leptin and hs-CRP levels than men.

As the relationship between hs-CRP and adiposity was similar in age-adjusted models and in fully-adjusted models (i.e. including age, cigarette smoking, alcohol consumption and physical activity) in both the Caucasian and African populations, we only present fully-adjusted models. All covariates included in the models had a linear relationship with adiposity measures with the exception of age in African men, in whom the relationship was convex.

The analytical relationship between hs-CRP and fat mass was clearly different in men and women for both Caucasian and African descent (Fig. 1). Moreover, the relationship between hs-CRP and fat mass was non-linear in both populations (Fig. 1). The increase in fat mass was markedly larger for low hs-CRP values and then attenuated at higher hs-CRP levels. At similar hs-CRP values, women had a higher fat mass than men. However these differences tended to disappear upon adjustment for leptin (only available in CoLaus). Results did not change when diabetic participants were excluded or when adjusting for HDL or HOMA (results not shown).
The analytical relation between hs-CRP and BMI was curvilinear in men up to hs-CRP values of $2 \mathrm{mg} / \mathrm{l}$ and then linear with 0 slope. In women, the relation between BMI and hs-CRP was curvilinear for low CRP levels and linear thereafter, but with a non null slope, in both populations (Fig. 1). We observed that African women had notably higher BMI than men, whereas this was not the case for Caucasians. For the same BMI, Caucasian women tended to have higher hs-CRP values than African women (Table 2).

\section{Discussion}

As expected, we found that the dose/response analytical relation between hs-CRP and adiposity differed in men and women in both the Caucasian and African populations. The present study also yielded novel findings. First, the analytical relationship between hs-CRP and adiposity was nonlinear. Second, this pattern of association was consistent across two ethnically different populations living in widely different environments. Finally, the sex difference in the relation between adiposity and hs-CRP was strongly attenuated upon adjustment for leptin.

Many studies have addressed sex differences in the relationship between hs-CRP and adiposity [14, 16-20] and have shown that correlations are stronger in women than men. However, most of them used linear models, which may not accurately reflect the true relation between hs-CRP and adiposity. The sex difference in the relationship between hs-CRP and adiposity seems to rely on different

Table 1 Participants' characteristics by sex and study population

\begin{tabular}{|c|c|c|c|c|}
\hline & \multicolumn{2}{|c|}{ CoLaus study (Caucasians) } & \multicolumn{2}{|c|}{ Seychelles' study (Africans) } \\
\hline & Men & Women & Men & Women \\
\hline$n$ & 2,906 & 3,213 & 524 & 645 \\
\hline Age (year) & $52.6(10.8)$ & $53.5(10.7)$ & $45.2(10.9)$ & $44.8(11.2)$ \\
\hline Height $(\mathrm{cm})$ & $175.0(7.3)$ & $162.7(6.7)$ & $171.7(7.0)$ & $159.9(6.3)$ \\
\hline Weight (kg) & $81.5(13.3)$ & $66.4(12.9)$ & $75.8(15.3)$ & $73.6(16.4)$ \\
\hline BMI $\left(\mathrm{kg} / \mathrm{m}^{2}\right)$ & $26.6(4.0)$ & $25.1(4.9)$ & $25.9(4.7)$ & $28.7(6.1)$ \\
\hline Fat mass $(\mathrm{kg})$ & $19.8(7.6)$ & $23.4(9.5)$ & $15.6(7.3)$ & $25.6(10.1)$ \\
\hline hs-CRP (mg/l) & $1.2(0.6-2.6)$ & $1.3(0.6-2.9)$ & $1.4(0.7-2.9)$ & $2.3(1.1-5.3)$ \\
\hline Leptin (ng/ml) & $6.4(3.9-10.8)$ & $14(8.2-23.0)$ & & \\
\hline Alcohol $^{\mathrm{a}}$ & $1,034(35.6)$ & $488(15.2)$ & $15.8(0-50.8)$ & $0(0-0)$ \\
\hline Current smokers (\%) & $852(29.3)$ & $802(25.0)$ & $160(30.5)$ & $22(3.41)$ \\
\hline Physical activity & $1,556(53.5)$ & $1,841(57.3)$ & $2,520(900-5,640)$ & $2,370(900-4,320)$ \\
\hline
\end{tabular}

Results are presented as mean with SD or median with interquartile range or as number of subjects and percentage

Physical activity is defined as number of persons with regular physical activity (at least 20 min twice a week) in Colaus, as median MET of physical activity per week for the Seychelles

${ }^{a}$ Alcohol is defined as number (\%) of regular alcohol drinkers (at least once a day) in Colaus, as median quantity with interquartile range per day in $\mathrm{ml}$ for the Seychelles 

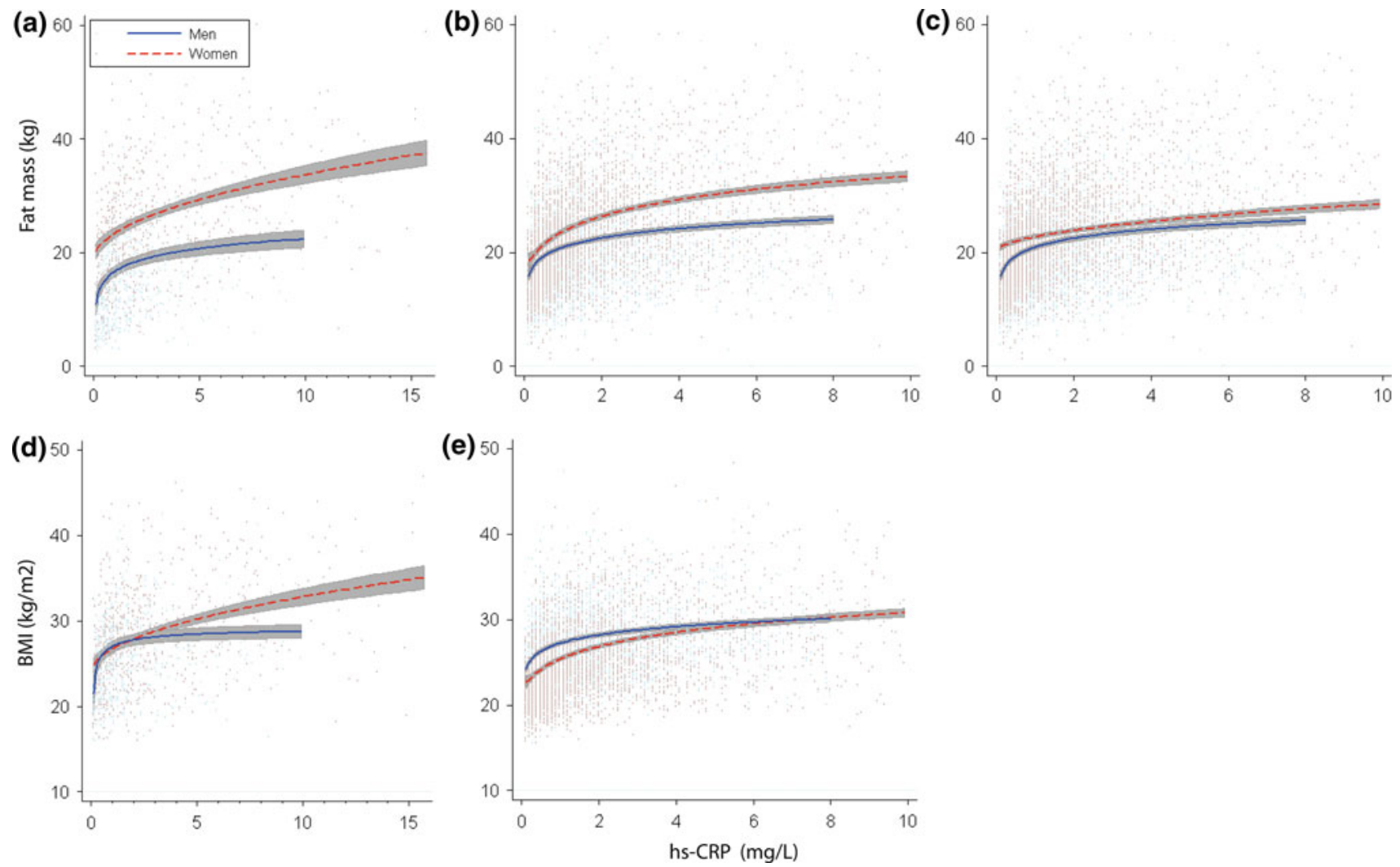

Fig. 1 Comparison of the relationship of hs-CRP with fat mass and BMI stratified by sex in CoLaus and the Seychelles' study Scatterplots of hs-CRP versus fat mass or body mass index by sex in the CoLaus study and in the Seychelles' study. Fractional polynomials are adjusted for age, cigarette smoking, alcohol consumption and physical activity. a Relationship between hs-CRP and fat mass in the

Table 2 Median hs-CRP according to body mass index and sex in the CoLaus study and in the Seychelles' study

\begin{tabular}{llll}
\hline & \multicolumn{2}{l}{ BMI class $\left(\mathrm{kg} / \mathrm{m}^{2}\right)$} \\
\hline Median hs-CRP $(\mathrm{mg} / \mathrm{l})$ & $<25$ & 25 to $<30$ & 30 \\
Women CoLaus & 0.8 & 1.9 & 3.8 \\
Women Seychelles & 1.6 & 2.1 & 4.1 \\
Men CoLaus & 0.8 & 1.4 & 2.1 \\
Men Seychelles & 1.0 & 1.65 & 1.9 \\
\hline
\end{tabular}

endocrine function of the adipose tissue, in women vs. men, and corresponding different production of cytokines and hormones that may increase hs-CRP levels. Indeed, one third of interleukin- 6 is produced in the adipose tissue and is involved in hs-CRP release from the liver [32, 33]. Another hypothesis is linked to the sex difference in leptin levels. In women, Abdullah et al. [31] described strong independent correlations between adiposity and leptin, on one hand, and between leptin and hs-CRP, on the other hand. Samara et al. [34] found a significant positive relation between leptin and CRP in women but not in men,
Seychelles. b Relationship between hs-CRP and fat mass in the CoLaus study. c Relationship between hs-CRP and fat mass in the CoLaus study, with additional adjustment for leptin. d Relationship between hs-CRP and body mass index in the Seychelles' study. e Relationship between hs-CRP and body mass index in the CoLaus study

using a model in which fat mass, among others, was included as a covariate. Our findings illustrated that sex difference in the relationship between hs-CRP and fat mass nearly disappeared upon adjustment with leptin, suggesting that leptin may mediate sex-related differences in the relationship between hs-CRP and fat mass. Plasma leptin levels are higher in women than men and a direct action of leptin on hs-CRP has been suggested [21, 35, 36]. Moreover, experimental evidence shows that leptin administration increases hs-CRP levels in humans [37]. It has also been suggested that the relationship between adiposity and hs-CRP is consistent across different ethnic groups [14, 17, 18]. Our study extends these findings to two ethnically different populations (Africans and Caucasians) living in different settings (Seychelles and Switzerland).

There are some limitations to this study. First, our results on the role of leptin, may not apply to non-Caucasians since leptin was measured only in the CoLaus study. Second, we could not adjust for statin and estrogen use in the Seychelles study. However, almost identical findings in these two different populations suggest that adjustments for 
these factors would not have had substantial impact. Strengths of the study are the use of a non-linear dose/ response relation between hs-CRP and the outcome that better and more realistically fits the data, the availability of data in two populations that have different ethnic background and live in completely different environments, and the population-based design of both studies, which increases the external validity of the findings. Also, we acknowledge that other regression models for handling non linearity would have likely yielded similar results.

In conclusion, we report a non-linear relation between hs-CRP and adiposity. This mathematical relation was steeper in women than men, in particular at low hs-CRP levels. Furthermore, our findings suggest that the sex difference in the relationship between adiposity and CRP might be mediated by leptin. Additional research is needed to further elucidate the mechanisms behind these findings.

Acknowledgments The Seychelles Heart Study III survey was funded in part by the Ministry of Health, Republic of Seychelles; the Institute of Social and Preventive of Medicine in Lausanne, Switzerland; and the Institute of Clinical Chemistry and Haematology, Kantonsspital, St-Gallen Prof Walter Riesen). The authors acknowledge the coordinating roles in the surveys of Julita William-Fostel, George Madeleine and Bharathi Viswanathan. Special thanks go to the Ministry of Health, Seychelles, for continuous support to epidemiological research. The CoLaus study was supported by research grants from GlaxoSmithKline and from the Faculty of Biology and Medicine of Lausanne, Switzerland. The authors express their gratitude to the participants in the Lausanne CoLaus study, to the investigators and key staff, in particular Yolande Barreau, Anne-Lise Bastian, Binasa Ramic, Martine Moranville, Martine Baumer, Marcy Sagette, Jeanne Ecoffey and Sylvie Mermoud for data collection, and to Allen Roses, Lefkos T. Midleton and Paul Matthews for their support. M. Bochud is supported by the Swiss School of Public Health Plus (SSPH+).

Conflict of interest The authors declare that they have no conflict of interest.

\section{References}

1. Koenig W, Sund M, Frohlich M, Fischer HG, Lowel H, Doring A, et al. C-Reactive protein, a sensitive marker of inflammation, predicts future risk of coronary heart disease in initially healthy middle-aged men: results from the MONICA (Monitoring Trends and Determinants in Cardiovascular Disease) Augsburg Cohort Study, 1984 to 1992. Circulation. 1999;99(2):237-42.

2. Albert CM, Ma J, Rifai N, Stampfer MJ, Ridker PM. Prospective study of C-reactive protein, homocysteine, and plasma lipid levels as predictors of sudden cardiac death. Circulation. 2002;105(22):2595-9.

3. Ridker PM, Rifai N, Rose L, Buring JE, Cook NR. Comparison of C-reactive protein and low-density lipoprotein cholesterol levels in the prediction of first cardiovascular events. N Engl J Med. 2002;347(20):1557-65.

4. Danesh J, Wheeler JG, Hirschfield GM, Eda S, Eiriksdottir G, Rumley A, et al. C-reactive protein and other circulating markers of inflammation in the prediction of coronary heart disease. N Engl J Med. 2004;350(14):1387-97.
5. Ridker PM. High-sensitivity C-reactive protein as a predictor of all-cause mortality: implications for research and patient care. Clin Chem. 2008;54(2):234-7.

6. Rost NS, Wolf PA, Kase CS, Kelly-Hayes M, Silbershatz H, Massaro JM, et al. Plasma concentration of C-reactive protein and risk of ischemic stroke and transient ischemic attack: the Framingham study. Stroke. 2001;32(11):2575-9.

7. Kaptoge S, Di AE, Lowe G, Pepys MB, Thompson SG, Collins $\mathrm{R}$, et al. C-reactive protein concentration and risk of coronary heart disease, stroke, and mortality: an individual participant meta-analysis. Lancet. 2010;375(9709):132-40.

8. Festa A, D'Agostino R Jr, Howard G, Mykkanen L, Tracy RP, Haffner SM. Chronic subclinical inflammation as part of the insulin resistance syndrome: the Insulin Resistance Atherosclerosis Study (IRAS). Circulation. 2000;102(1):42-7.

9. Ford ES. Body mass index, diabetes, and C-reactive protein among US adults. Diabetes Care. 1999;22(12):1971-7.

10. Yudkin JS, Stehouwer CD, Emeis JJ, Coppack SW. C-reactive protein in healthy subjects: associations with obesity, insulin resistance, and endothelial dysfunction: a potential role for cytokines originating from adipose tissue? Arterioscler Thromb Vasc Biol. 1999;19(4):972-8.

11. Laaksonen DE, Niskanen L, Nyyssonen K, Punnonen K, Tuomainen TP, Valkonen VP, et al. C-reactive protein and the development of the metabolic syndrome and diabetes in middleaged men. Diabetologia. 2004;47(8):1403-10.

12. Wong ND, Pio J, Valencia R, Thakal G. Distribution of C-reactive protein and its relation to risk factors and coronary heart disease risk estimation in the National Health and Nutrition Examination Survey (NHANES) III. Prev Cardiol. 2001;4(3): 109-14.

13. Hak AE, Stehouwer CD, Bots ML, Polderman KH, Schalkwijk $\mathrm{CG}$, Westendorp IC, et al. Associations of C-reactive protein with measures of obesity, insulin resistance, and subclinical atherosclerosis in healthy, middle-aged women. Arterioscler Thromb Vasc Biol. 1999;19(8):1986-91.

14. Festa A, D'Agostino R Jr, Williams K, Karter AJ, Mayer-Davis EJ, Tracy RP, et al. The relation of body fat mass and distribution to markers of chronic inflammation. Int $\mathrm{J}$ Obes Relat Metab Disord. 2001;25(10):1407-15.

15. Pou KM, Massaro JM, Hoffmann U, Vasan RS, MaurovichHorvat P, Larson MG, et al. Visceral and subcutaneous adipose tissue volumes are cross-sectionally related to markers of inflammation and oxidative stress-The Framingham heart study. Circulation. 2007;116(11):1234-41.

16. Visser M, Bouter LM, McQuillan GM, Wener MH, Harris TB. Elevated C-reactive protein levels in overweight and obese adults. JAMA. 1999;282(22):2131-5.

17. Lear SA, Chen MM, Birmingham CL, Frohlich JJ. The relationship between simple anthropometric indices and C-reactive protein: ethnic and gender differences. Metabolism. 2003;52(12): 1542-6.

18. Khera A, McGuire DK, Murphy SA, Stanek HG, Das SR, Vongpatanasin $\mathrm{W}$, et al. Race and gender differences in C-reactive protein levels. J Am Coll Cardiol. 2005;46(3):464-9.

19. Thorand B, Baumert J, Doring A, Herder C, Kolb H, Rathmann $\mathrm{W}$, et al. Sex differences in the relation of body composition to markers of inflammation. Atherosclerosis. 2006;184(1):216-24.

20. Khera A, Vega GL, Das SR, Ayers C, McGuire DK, Grundy SM, et al. Sex differences in the relationship between C-reactive protein and body fat. J Clin Endocrinol Metab. 2009;94(9): 3251-8.

21. Bochud M, Marquant F, Marques-Vidal PM, Vollenweider P, Beckmann JS, Mooser V, et al. Association between C-reactive protein and adiposity in women. J Clin Endocrinol Metab. 2009;94(10):3969-77. 
22. Timpson NJ, Lawlor DA, Harbord RM, Gaunt TR, Day IN, Palmer LJ, et al. C-reactive protein and its role in metabolic syndrome: Mendelian randomisation study. Lancet. 2005; 366(9501):1954-9.

23. Welsh P, Polisecki E, Robertson M, Jahn S, Buckley BM, de Craen AJ, et al. Unraveling the directional link between adiposity and inflammation: a bidirectional Mendelian randomization approach. J Clin Endocrinol Metab. 2010;95(1):93-9.

24. Elliott P, Chambers JC, Zhang W, Clarke R, Hopewell JC, Peden $\mathrm{JF}$, et al. Genetic loci associated with C-reactive protein levels and risk of coronary heart disease. JAMA. 2009;302(1):37-48.

25. Bovet P, Shamlaye C, Gabriel A, Riesen W, Paccaud F. Prevalence of cardiovascular risk factors in a middle-income country and estimated cost of a treatment strategy. BMC Public Health. 2006;6(9):9.

26. World Health Organization [Internet]. Geneva: Global physical activity surveillance. 2010 [updated 2010; cited 2010 Feb 25]. Available from: http://www.who.int/chp/steps/GPAQ/en/index.html.

27. Firmann M, Mayor V, Vidal PM, Bochud M, Pecoud A, Hayoz D, et al. The CoLaus study: a population-based study to investigate the epidemiology and genetic determinants of cardiovascular risk factors and metabolic syndrome. BMC Cardiovasc Disord. 2008;8:6.

28. Levy JC, Matthews DR, Hermans MP. Correct homeostasis model assessment (HOMA) evaluation uses the computer program. Diabetes Care. 1998;21(12):2191-2.

29. Royston P, Ambler G, Sauerbrei W. The use of fractional polynomials to model continuous risk variables in epidemiology. Int $\mathrm{J}$ Epidemiol. 1999;28(5):964-74.

30. Royston P, Sauerbrei W. Multivariable modeling: a pragmatic approach based on fractional polynomials for continuous variables. Chichester, UK: Wiley-Blackwell; 2008.
31. Abdullah SM, Khera A, Leonard D, Das SR, Canham RM, Kamath SA, et al. Sex differences in the association between leptin and CRP: results from the Dallas Heart Study. Atherosclerosis. 2007;195(2):404-10.

32. Moshage HJ, Roelofs HM, van Pelt JF, Hazenberg BP, van Leeuwen MA, Limburg PC, et al. The effect of interleukin-1, interleukin-6 and its interrelationship on the synthesis of serum amyloid A and C-reactive protein in primary cultures of adult human hepatocytes. Biochem Biophys Res Commun. 1988; 155(1):112-7.

33. Mohamed-Ali V, Goodrick S, Rawesh A, Katz DR, Miles JM, Yudkin JS, et al. Subcutaneous adipose tissue releases interleukin-6, but not tumor necrosis factor-alpha, in vivo. J Clin Endocrinol Metab. 1997;82(12):4196-200.

34. Samara A, Herbeth B, Aubert R, Berrahmoune H, Fumeron F, Siest G, et al. Sex-dependent associations of leptin with metabolic syndrome-related variables: the Stanislas Study. Obesity. 2010;18(1):196-201.

35. Zhang YY, Gottardo L, Mlynarski W, Frazier W, Nolan D, Duffy $\mathrm{J}$, et al. Genetic variability at the leptin receptor (LEPR) locus is a determinant of plasma fibrinogen and C-reactive protein levels. Atherosclerosis. 2007;191(1):121-7.

36. Chen K, Li F, Li J, Cai H, Strom S, Bisello A, et al. Induction of leptin resistance through direct interaction of C-reactive protein with leptin. Nat Med. 2006;12(4):425-32.

37. Hukshorn CJ, Lindeman JH, Toet KH, Saris WH, Eilers PH, Westerterp-Plantenga MS, et al. Leptin and the proinflammatory state associated with human obesity. J Clin Endocrinol Metab. 2004;89(4):1773-8. 